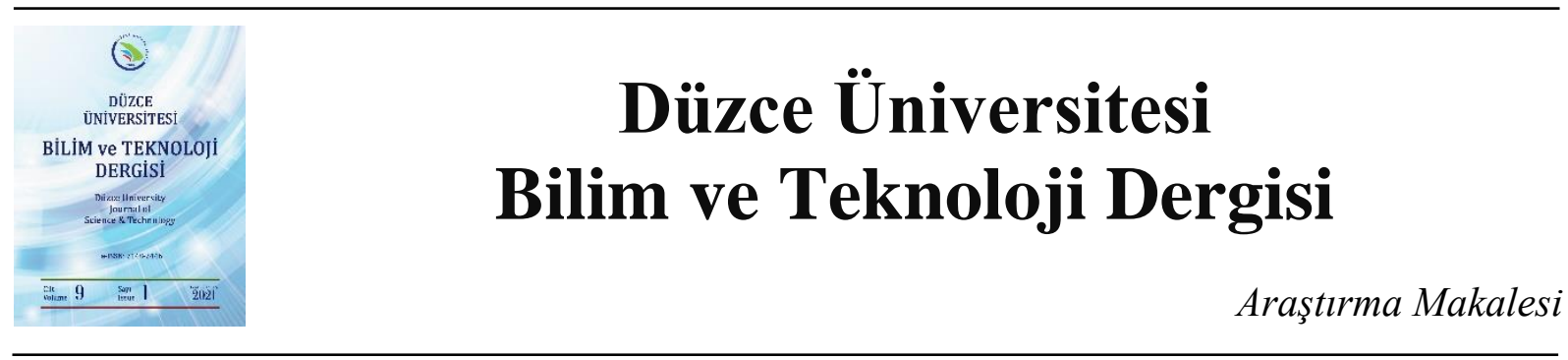

\section{İkili Çarpan Jet ile Soğutulan Sıcak Plakanın Yüzey Şeklinin Isı Transferine Etkisinin Sayısal Analizi}

\author{
Hüseyin KAYA ${ }^{a, *}$ \\ ${ }^{a}$ Makine Mühendisliği Bölümü, Mühendislik, Mimarlık ve Tasarım Fakültesi, Bartın Üniversitesi, Bartın, \\ TÜRKIYE \\ * Sorumlu yazarin e-posta adresi: hkaya@personel.bartin.edu.tr
}

DOI: $10.29130 /$ dubited.754908

\begin{abstract}
ÖZET
$\mathrm{Bu}$ çalışmada sıcak bir plakanın çarpan jet akışla soğutulmasının ısı transferi ve akış karakteristikleri hesaplamalı akışkanlar dinamiği yöntemi ile sayısal olarak incelenmiştir. Sıcak plakanın aynı yükseklikteki düz, zikzak, yamuk ve dikdörtgen kesitli geometrileri için ikili nozul sistemi kullanılarak türbülanslı çarpan jet akış ile soğutulması durumunda ısı transferi ve hidrolik performanslar karşılaştırılmıştır. Hesaplamalarda çalışma akışkanı olarak hava kullanılmış olup, taşınımla gerçekleşen ısı transferi performansının analizi için ortalama ve yerel Nusselt $(\mathrm{Nu})$ sayılarının dağılımı elde edilmiştir. Hidrolik performans için pompalama gücü değerleri karşılaştııılmıştır. Türbülanslı çarpan jet akış için k-E türbülans - duvar yakın modelinin kullanılmıştır. Elde edilen sonuçlara göre, yamuk kesitli plakanın en yüksek ısıl performansa sahip olduğu ve taşınımla gerçekleşen 1sı transfer hızı aynı şartlarda düz plakadan yaklaşık $\% 52,2$ daha yüksek olduğu belirlenmiştir. Termo-hidrolik performans açısından Nusselt sayısı/Pompalama Gücü oranı hesaplanmış ve en düşük performansın basınç farkının en yüksek olmasından dolayı dikdörtgen kesit için oluștuğu gözlemlenmiștir. Bununla birlikte yerel Nusselt sayılarının dağılımına bakıldığında, nozulların çarptığı noktalarda en yüksek değerleri alıp çıkış kısımlarına doğru azaldığı belirlenmiştir. Çarpan jetler kullanılarak soğutma işlemi yapılan sıcak plaka yüzey kesit şeklinin taşınımla gerçekleşen ısı transferini önemli ölçüde arttırdığı görülmüştür.
\end{abstract}

Anahtar kelimeler: Çarpan jet akış, İkili jet, Isl transferi, $H A D$

\section{Numerical Analysis of the Effect of Surface Shape of Hot Plate Cooled by Double Impinging Jet on Heat Transfer}

\begin{abstract}
In this study, heat transfer and flow characteristics of cooling of a hot plate with impinging jet flow were investigated numerically by computational fluid dynamics method. Heat transfer and hydraulic performances were compared in the case of cooling of the hot plate with turbulent impinging jet flow using a twin nozzle system for flat, zigzag, trapezoid and rectangular geometries of the same height. Air is used as the working fluid in the calculations and the distribution of average and local Nusselt $(\mathrm{Nu})$ numbers is obtained for the analysis of heat transfer performance. Pumping power values were compared for hydraulic performance. For turbulent impinging jet flow, the k- $\varepsilon$ turbulence model - near wall treatment is used. According to the results obtained, the trapezoidal plate has the highest thermal performance with 115,67 Nusselt number value and this value is approximately $52,2 \%$ higher than flat plate under the same conditions. In terms of thermo-hydraulic performance, the Nusselt number / Pumping Power ratio was calculated, and it was determined that the lowest performance occurred for the rectangular section due to the highest-pressure difference. However, when looking at the distribution of local Nusselt numbers, it was determined that the nozzles hit the highest values and decreased towards the exit parts. It
\end{abstract}


has been observed that the hot plate surface section shape, which is cooled using impinging jets, significantly affects the heat transfer.

Keywords: Impinging jet flow, Double jet, Heat transfer, CFD

\section{GIRIS}

Isıl-enerji sistemleri için 1sı transferi kapasitesini artırmak amacıyla yapılan uygulamalar her daim önemli olmuştur. Bunlardan biri olan çarpan jet akış yöntemi ile endüstride birçok soğutma uygulaması yapılmaktadır. Bunlardan bazıları gıda kurutma, 1sıl işlemler, elektronik bileşenlerin soğutulması, gaz türbini parçalarının soğutulması olup, kâğıt, tekstil ve kaplama endüstrisinde de soğutma amaçlı kullanılmaktadır [1]-[3]. Sıcak yüzeye akışkan çarptırılarak soğutma işlemi gerçekleştirilir. Genellikle nozul olarak adlandırılan dairesel kesitli jet deliklerinden yollanan akışkan sıcak yüzeye çarptırılır ve burada ince bir sınır tabaka meydana gelir ve bu sınır tabaka 1sı transferinin artmasını sağlar. Bununla birlikte yüksek momentum aktarım hızı da çarpan jet akışlı soğutmayı etkin hale getirmektedir. Genel uygulamalarda ucuz ve temin edilebilirliği kolay olduğundan çalışma akışkanı olarak hava kullanılmaktadır [4], [5].

Son çalışmalara bakıldığında çarpan jet akışla soğutma uygulamasının 1sı1-akış analizi ile ilgili olarak jet çapının, plaka jet uzaklığının, akış rejiminin performansa etkilerinin incelendiği çalışmalar görülmektedir [6]-[8]. Attalla ve Salem tarafından yapılan deneysel çalışmada yatay plaka üzerine eğimli bir nozul sistemi kullanılarak türbülanslı jet akışı yüzeye çarptırılarak yüzey üzerindeki 1sı transferi karakteristikleri incelenmiştir. Nozul eğim açısı, nozul-plaka uzaklığı ve akış Reynolds sayısına $(\mathrm{Re})$ göre akışın Nusselt sayısının $(\mathrm{Nu})$ ortalama ve yerel değerlerinin değişimi elde edilerek $\mathrm{Nu}$ sayısı için korelasyonlar türetilmiştir. Belirtilen sonuçlara göre jet nozul eğim açısı azaldıkça maksimum isı transferi azalmakta ve maksimum 1sı transfer noktası çarpma noktasından geriye doğru hareket etmektedir [9]. Achari vd. tarafından yapılan çalışmada, farklı hızlarda hareket eden sıcak bir plakaya çarpan jet akışın uygulanması durumundaki ısı transferi sayısal olarak modellenmiştir. Hedef plaka sabit sıcaklık sınır şartı uygulanarak türbülanslı akış şartlarında analiz gerçekleştirilmiştir. Eşlenik (conjugate) 1si transferi analizi yapılarak nozul ve hareket halindeki plaka birlikte ele alınmıştır. Farklı yüzey-jet hız oranlarına göre toplam hız, basınç dağılımı ve yerel kayma gerilmeleri incelenmiştir. Bununla birlikte akışkan - katı etkileşim sıcaklıkları, yerel Nu sayısı ve 1sı akısı değişimleri kullanılarak eşlenik 1sı transferi irdelenmiştir [10]. İçbükey ve dış bükey yüzeyler üzerindeki çarpan jet akışın etkilerini irdeleyen deneysel bir çalışma, Kim vd. tarafından sabit yüzey sıcaklığı koşulunda laminer akış şartlarında gerçekleştirilmiştir. Re sayısı, nozul-yüzey uzaklığı ve hedef yüzey geometrisinin 1Sı transferi performansına etkisi incelenmiş olup, içbükey plakada elde edilen maksimum yerel Nu sayısı, aynı şartlardaki dışbükey plakada elde edilenden \%47 daha yüksek olduğu belirtilmiştir [11]. Rim vd.'nin yaptığı çalışmada nozul - plaka mesafesinin türbülanslı çarpan jet akışı ile soğutulması durumdaki ısı transferi karakteristikleri deneysel olarak incelenmiştir. Bununla birlikte toplam akışı incelemek için 3-boyutlu bir sayısal analiz de gerçekleştirilmiştir. Farklı akış şartlarındaki sıcaklık ve türbülans dağılımları irdelenmiştir. Nozul - plaka mesafesinin küçük değerleri için elde edilen ortalama hız ve ısı transferi performansının büyük değerler için olanlara göre oldukça farklı olduğunu bildirmişlerdir. İlave olarak düşük nozul - plaka mesafeleri için, duvar kayma gerilmesi dağılımı ve duvar basıncının belirgin özellik gösterdiği belirtilmiştir [8]. Asimetrik içbükey geometriye sahip bir plakanın soğutulmasında, sinüs dalgası şeklinde zamana bağlı modellenen türbülanslı bir çarpan jet akışının 1sı ve akış performansı Zargarabadi vd. tarafından sayısal olarak incelenmiştir. Elde ettikleri sonuçlara göre, $40-160 \mathrm{~Hz}$ frekans aralığındaki sinüs dalgası zamana bağlı Nu seyısında \%2-8 aralığında artış sağlamıştır. Ayrıca, düşük bağıl eğriliğe sahip yüzeylerde zamana bağlı Nu sayısı değerleri daha büyük olarak elde edilmiştir. Optimum yanal mesafenin ortalama Nu sayısını $\% 5$ artırdığı belirlenmiştir [12]. Park vd. tarafından düzlemsel duvara, yüzeyi süpürme hareketi ile çarpan jet akışın 1sı transferi ve akış yapısı analizi deneysel olarak çalışılmıştır. Yerel Nu sayıları ve parçacık hızı görüntüleme yöntemi ile akış karakteristiği elde edilmiştir. Süpürme jet akışının uygulandığı yüzey merkezine yakın bölgelerde yükssek $\mathrm{Nu}$ sayısı bölgesinin olduğu tespit edilmiş olup, merkezden uzaklaşıldıkça $\mathrm{Nu}$ sayısının monoton olarak azaldığı gözlenmiştir. Ortalama yanal hız ve yanal hız dalgalanmalarının her 
iki bölgede tamamen farklı davranış gösterdiği belirtilmiştir [13]. Tepe vd. tarafindan yapılan sayısal çalışmada genişletilmiş jet nozullarının çapan jet akış performansı üzerindeki etkisi türbülans akış koşullarında $(\operatorname{Re}=15000$ - 45000) incelenmiş olup, oluklu yüzey ve düz yüzey için sonuçlar verilmiştir [14]. 2-boyutlu diğer bir sayısal çalışmada Ekiciler vd. tarafından modellenen çarpan jet akışının, farklı geometrideki yüzeyler üzerindeki akış ve 1sı transferi performansı incelenmiştir. Laminar akış koşullarında ( $\mathrm{Re}=100-500)$ gerçekleştirilen çalışmada sinüs dalgası şekline sahip yüzey 1sı transferi performansının daha yüksek olduğu belirtilmiştir [15]. Farklı geometrilere sahip akış yönlendiriciler kullanılarak sıcak bir plakanın 1sı transferi performansı çarpan jet akış koşullarında inceleyen sayısal bir çalışma Kılıç ve Başkaya tarafından gerçekleştirilmiştir. Silindirik, kare ve üçgen akış yönlendiriciler arasında en verimli 1sı transferi performansı üçgen olanla elde edilmiştir [16]. Çalışır vd. tarafindan yapılan diğer sayısal bir çalışmada nozul-plaka mesafesi ve kanatçık geometrisinin çarpan yüzeyin ısı ve akış performansına etkisi türbülanslı akış koşullarında incelenmiştir. $\mathrm{H} / \mathrm{d}=2$ (nozul - plaka uzaklık oranı) durumunda duvar jet akışlarının daha etkili olduğunu belirtmişlerdir [17]. Javadi tarafından yapılan sayısal çalışmada çarpan jet akışının çapraz akış koşullarındaki 1sı transferi davranışına, akış alanına yerleştirilen kanatçık girdap üretici çiftin etkisi incelenmiştir. URANS ve LES türbülans modelleri kullanılarak yürütülen çalışmada akış Re sayısı aralığı 15000-30000 arasında değiştirilmiştir. Girdap kanatçıklarının kullanılmasının çarpma yüzeyin Nu sayısını artırdığı ancak akış kararsızlıkları oluşturduğu gözlemlenmiştir [18].

Yapılan çalışmalara bakıldığında 1sı transferi performansı analizi için çoklu nozul kullanılarak farklı çarpan yüzey geometrileri ile ilgili ilave çalışmalara ihtiyaç olduğu değerlendirilmiştir. Bu kapsamda, ikili nozul kullanılan çarpan jet akışla soğutulan yüzeydeki taşınımla gerçekleşen 1sı transferi karakteristikleri farklı yüzey geometrileri için (zigzag, dikdörtgen ve yamuk kesitli) çalışılmıştır. Yüzey $\mathrm{Nu}$ sayısı ve yerel $\mathrm{Nu}$ sayısının değerleri hesaplanarak yorumlanmıştır.

\section{PROBLEM TANIMI VE FIZIKSSEL MODEL}

Isı ve akış performansı sayısal olarak incelenen ikili nozula sahip çarpan jet akış ile soğutma uygulamasının fiziksel modeli Şekil 1'de verilmiştir. Nozullardan gelen jet akış sıcak olan hedef yüzeye çarptıktan sonra sağ ve sol tarafta bulunan ve atmosfere açılan çıkış kısımlarından sistemi terk etmektedir. Jet akış nozullarının bulunduğu üst duvar kısmı sınırlı duvar olup adyabatik koşuldadır. Burada a, b ve w, sırasıyla hedef yüzeyin genişlik, derinlik ve kalınlık değerleri olup jet nozullarının çapı d olarak belirtilmiştir. Çarpma yüzeyi ölçüleri olan $a=300 \mathrm{~mm}, b=300 \mathrm{~mm}$ ve $w=10 \mathrm{~mm}$ olup jet nozullarının çapı ise $\mathrm{d}=20 \mathrm{~mm}$ olarak modellenmiştir. Yapılan çalışma $17000<\operatorname{Re}<25000$ için gerçekleştirilmiştir.

Sayısal analiz için modellenen hesaplama alanı için kullanılan sınır şartları aşağıda verilmiş olup, bunların dışında kalan katı duvarlarda adyabatik ve sıcak olan hedef yüzey için kaymaz sınır şartı kullanılmıştır. İkili nozul çarpan jet sisteminde hedef yüzeyi soğutmak için akışkan olarak hava ve kullanılmış olup, farklı geometrideki yüzeylerdeki performansı incelenmiştir. Hava akışının sayısal analizi için 3-boyutlu kararlı türbülanslı akış ve Newton tipi sıkıştırılamaz akışkan kabulleri yapılmıştır.

Sıcak olan hedef yüzeyde sabit sıcaklık sınır şartı kullanılmış olup bu değer $100{ }^{\circ} \mathrm{C}$ 'dir. Çarpan jet akış nozullarından gelen akışkan için türbülanslı akış koşulları için belirlenen Reynolds (Re) sayısından elde edilen hız değeri ve $30^{\circ} \mathrm{C}$ sıcaklık değeri giriş sınır şartları olarak uygulanmıştır. Giriş için belirtilen hız ve sıcaklık parametreleri uniform dağılım olarak uygulanmıştır. Çıkış kısımlarında ise atmosfere açıldığı için çıkış basıncı sınır şartı uygulanmış olup hücre sayısını ve dolaysıyla hesaplama süresini azalmak amacıyla kontrol hacminde simetri düzlemi $(\mathrm{x}-\mathrm{y})$ oluşturulmuş ve simetri sınır şartı uygulanmıştır. Simetri düzlemi Şekil 1'de mavi renkte belirtilmiştir. Simetri sınırını aşan herhangi bir akış veya ısı üretiminin olmadığı kabul edilmiştir. 


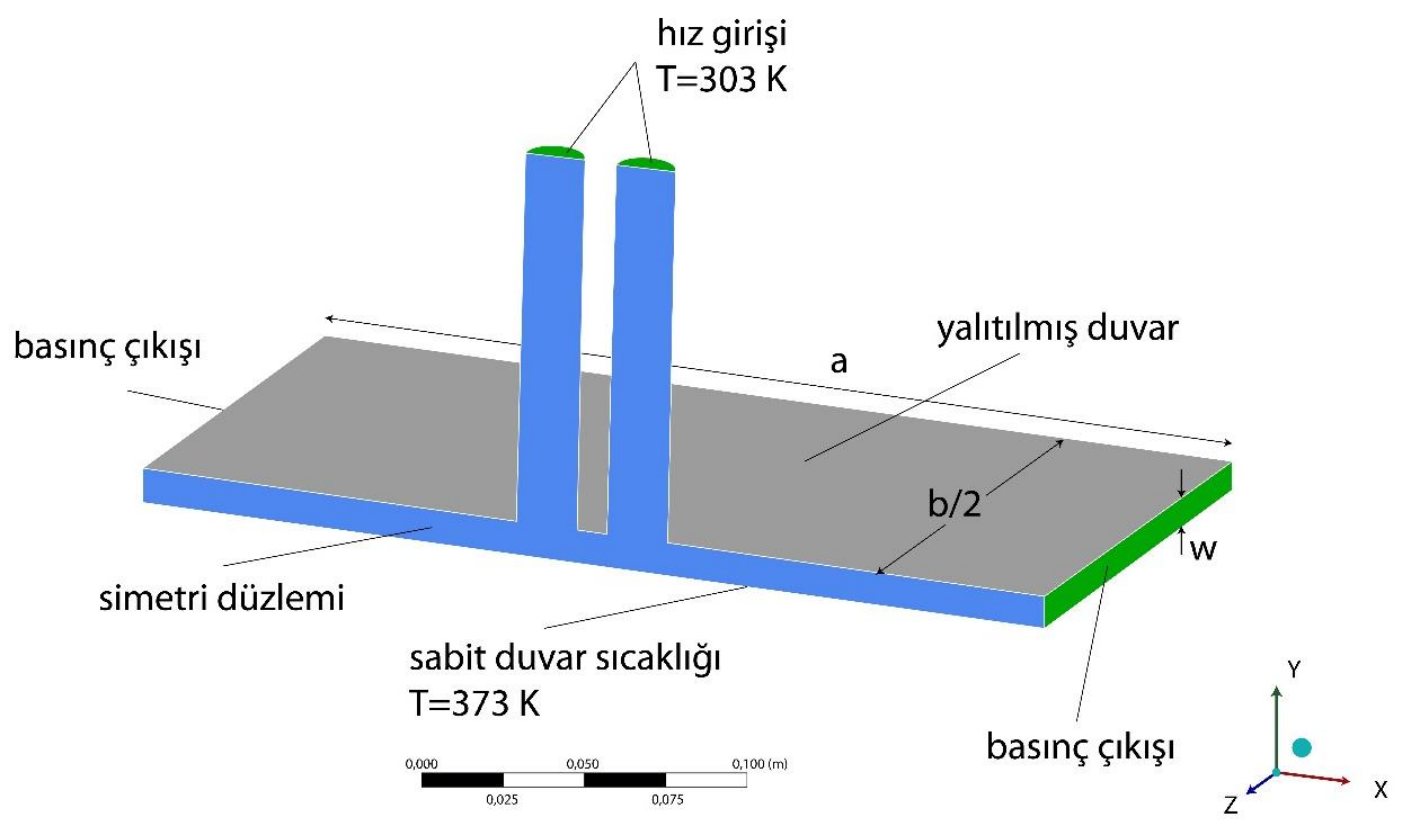

Şekil 1. Íkili nozul çarpan jet akış fiziksel modeli (düz yüzey için)

Çarpan jet akışının türbülanslı durumunun analizi için literatürde farklı türbülans modelleri kullanılmıştır. Bunlardan yaygın olarak kullanılanlar K-epsilon $(\mathrm{k}-\varepsilon)$ ve K-omega $(\mathrm{k}-\omega)$ olup k- $\varepsilon$ modelinin hata oranı daha düşük sonuçlar verdiği belirtilmiştir [19] . İki adet taşınım denkleminden oluşan bu türbülans modelinde, kinetik enerji $(\mathrm{k})$ ve türbülans yayılım oranı $(\varepsilon)$ türbülanslı akışı karakterize ederek özgün bir çözüm sunmaktadır. k- $\varepsilon$ türbülans modelinin Re-Normalizasyon Grup (RNG) modülü, Navier-Stokes denklemlerinin yeniden normalleştirilmesiyle elde edilmiş olup, standart modüle oranla akışın daha küçük hareketlerini de hesaba kattığından daha hassas sonuçlar vermektedir. Bu kapsamda çalışmada k- $\varepsilon$ RNG türbülans modeli kullanılmış olup 1şınım 1sı transferi etkileri ihmal edilmiştir. Türbülanslı akış Ansys Fluent 18.2 paket programı kullanılarak çözülmüştür. Üç boyutlu sayısal analizinde kullanılan süreklilik, momentum ve enerji denklemleri aşağıda verilmiştir.

Süreklilik:

$\frac{\partial u}{\partial x}+\frac{\partial v}{\partial y}+\frac{\partial w}{\partial z}=0$

$\mathrm{x}, \mathrm{y}$ ve $\mathrm{z}$ momentum:

$$
\begin{aligned}
& \rho\left(u \frac{\partial u}{\partial x}+v \frac{\partial u}{\partial y}+w \frac{\partial u}{\partial z}\right)=-\frac{\partial p}{\partial x}+\rho g_{x}+v\left(\frac{\partial^{2} u}{\partial x^{2}}+\frac{\partial^{2} u}{\partial y^{2}}+\frac{\partial^{2} u}{\partial z^{2}}\right) \\
& \rho\left(u \frac{\partial v}{\partial x}+v \frac{\partial v}{\partial y}+w \frac{\partial v}{\partial z}\right)=-\frac{\partial p}{\partial y}+\rho g_{y}+v\left(\frac{\partial^{2} v}{\partial x^{2}}+\frac{\partial^{2} v}{\partial y^{2}}+\frac{\partial^{2} v}{\partial z^{2}}\right) \\
& \rho\left(u \frac{\partial w}{\partial x}+v \frac{\partial w}{\partial y}+w \frac{\partial w}{\partial z}\right)=-\frac{\partial p}{\partial z}+\rho g_{z}+v\left(\frac{\partial^{2} w}{\partial x^{2}}+\frac{\partial^{2} w}{\partial y^{2}}+\frac{\partial^{2} w}{\partial z^{2}}\right)
\end{aligned}
$$

\section{Enerji:}


$u \frac{\partial T}{\partial x}+v \frac{\partial T}{\partial y}+w \frac{\partial T}{\partial z}=\alpha\left(\frac{\partial^{2} T}{\partial x^{2}}+\frac{\partial^{2} T}{\partial y^{2}}+\frac{\partial^{2} T}{\partial z^{2}}\right)$

Denklemlerde belirtilen değişkenlerden $\rho, v$ ve $\alpha$ sırasıyla çalışma akışkanın yoğunluk, kinematik viskozite ve termal difüzivite değerleridir.

İki denklemli türbülans modeli için kullanılan türbülans kinetik enerji ve türbülans dağılım oranı denklemleri (6) ve (7) ile verilmiştir.

$$
\begin{aligned}
& \frac{\partial}{\partial t}(\rho k)+\frac{\partial}{\partial x_{i}}\left(\rho k u_{i}\right)=\frac{\partial}{\partial x_{j}}\left[\left(\mu+\frac{\mu_{t}}{\sigma_{k}}\right) \frac{\partial k}{\partial x_{j}}\right]+G_{k}+G_{b}-\rho \varepsilon-Y_{M}+S_{K} \\
& \frac{\partial}{\partial t}(\rho \varepsilon)+\frac{\partial}{\partial x_{i}}\left(\rho \varepsilon u_{i}\right)=\frac{\partial}{\partial x_{j}}\left[\left(\mu+\frac{\mu_{t}}{\sigma_{\varepsilon}}\right) \frac{\partial \varepsilon}{\partial x_{j}}\right]+C_{1 \varepsilon} \frac{\varepsilon}{k}\left(G_{k}+C_{3 \varepsilon} G_{b}\right)-C_{2 \varepsilon} \rho \frac{\varepsilon^{2}}{k}+S_{\varepsilon}
\end{aligned}
$$

$G_{k}$ ve $G_{b}$ sırasıyla ortalama hız gradyanlarına ve kaldırma kuvvetine dayalı türbülans kinetik enerjisi üretimidir. $\mathrm{Y}_{\mathrm{M}}$, sıkıştırılabilir türbülans için dalgalı dilatasyon terimidir. $C_{l \varepsilon}, C_{2 \varepsilon}$ ve $C_{3 \varepsilon}$ sabitler olup, $\sigma_{k}$ ve $\sigma_{\varepsilon}, k$ ve $\varepsilon$ için Prandtl sayılarıdır.

Isı transferi performansını incelemek için farklı Reynolds sayılarında (denklem 8) analizle yapılmış ve çarpan jet akışının ortalama ve yerel Nusselt sayısı dağılımları denklemler (9) ve (10) kullanılarak hesaplanmıştır.

$$
\begin{aligned}
& \operatorname{Re}=\frac{\rho V D_{h}}{\mu} \\
& N u_{\text {ort }}=\frac{h D_{h}}{k} \\
& N u_{x}=\frac{h_{x} D_{h}}{k}
\end{aligned}
$$

$D_{h}$, hidrolik çap ve $k$, çalışma akışkanı ısıl iletkenliğidir. h, taşınım 1sı transferi katsayısını, $V$ akışkanın hızını ve $\mu$ ise dinamik viskoziteyi ifade eder. Hidrolik performansı belirlemek için pompalama gücü denklem (11) kullanılarak hesaplanmıştır.

$$
P G=\dot{V}\left(P_{i}-P_{o}\right)
$$

Sayısal analiz prosedürü dört adımda gerçekleştirilmiş olup bunlar, akış geometrisinin hazırlanması, uygun ağ yapısının oluşturulması, sınır şartlarının uygulanması ve çözüm olarak belirlenmiştir. Çözüm sonucunda elde edilen verilen kullanılarak yapılan hesaplamalar ile sonuçlar yorumlanmıştır. 


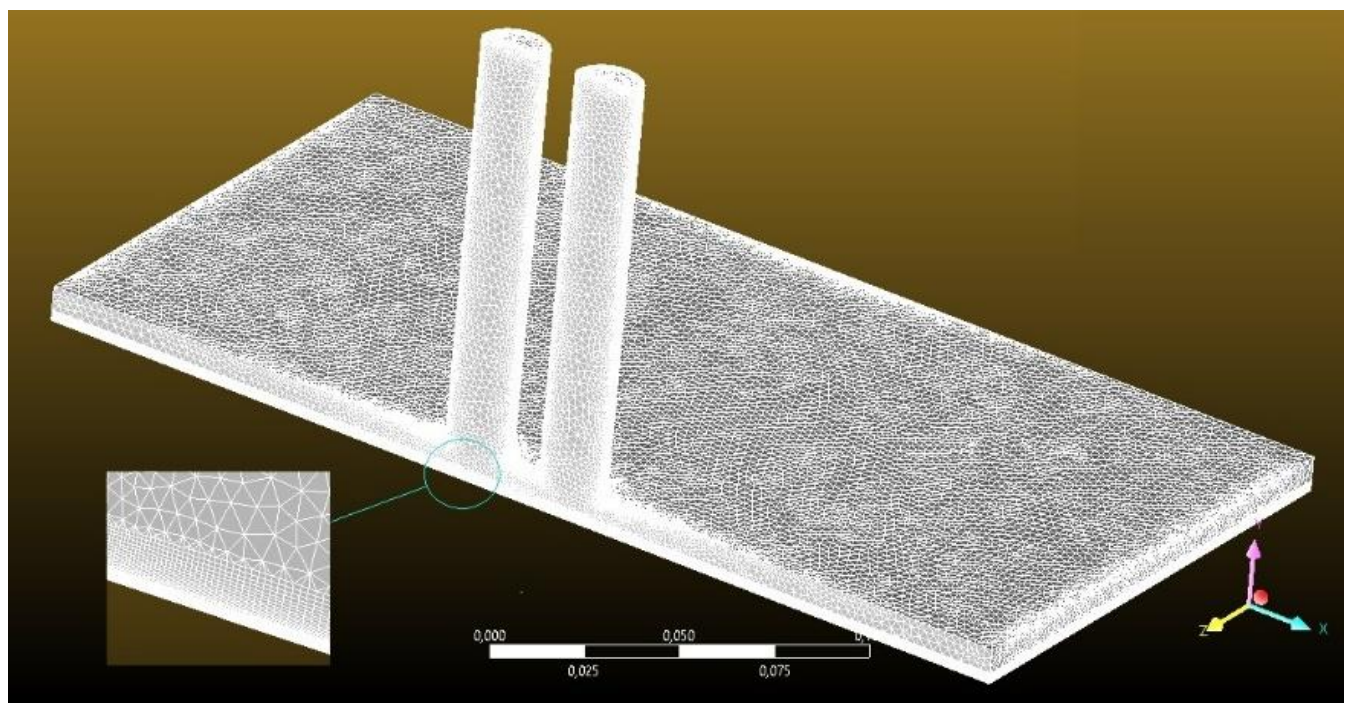

Şekil 2. Sayısal modelin ă̆ yapısının dağıllımı

Hesaplamalı akışkanlar dinamiği (HAD) için kurulan sayısal modelde uygun ağ yapısının oluşturulması, çözümün doğruluğu ve güvenirliği açısından çok önemlidir. Çözüm için oluşturulan ağ yapısında tetrahedron ağ yapısı kullanılmış olup düzgün hücre dağılımı elde etmek için duvarlara yakın kısımlarda sınır tabaka ağ yapısı oluşturulmuştur. Ana akış yönüne dik olan düzleme, düzgün olmayan ağ yapısı uygulanmış olup, çözümün doğruluğunu artırmak için jet akışın çarptı̆̆ hedef yüzeyin duvarlara yakın bölgesinde ağ yapısı yoğunlaştırılmıştır. Belirlenen sınır şartları kullanılarak, süreklilik, momentum ve enerji denklemleri için sayısal çözüm Ansys - Fluent 18.2 yazılımı ile $10^{-5}$ artık hata oranı sınırı uygulanarak gerçekleştirilmiş ve çözümlerde herhangi bir yakınsama problemi gözlenmemiştir. Hız, basınç ile Basınç Bağlantılı Denklemler için Yarı Örtülü Yöntem (SIMPLE) ile birleştirilerek çözüm yapılmıştır. A ̆g yapısının dağılımı Şekil 2'de verilmiştir.

Sayısal analizde elde edilen sonuçların modelin ağ yapısının dağılımdan bağımsız olması amaciyla hücre sayısı optimizasyonu yapılması çözüm için önemli bir adımdır. Bu amaçla bu çalışmada hücre sayısı optimizasyonu yapılmış ve daha önce yapılan deneysel çalışma ile karşılaş̧ırılmıştır [20]. Jet nozullarından hedef yüzeye çarpan akışın sonucunda elde yüzeyin taşınım 1sı transferi katsayısı bu karşılaştırma için kullanılmıştır. $\mathrm{Re}=17000$ için bulunan $56,217 \mathrm{~W} / \mathrm{m}^{2} \mathrm{~K}$ değerinden elde edilen 46,45 $\mathrm{Nu}$ sayısı doğrulama değeri olarak alınmıştır. Elde edilen sonuçlara göre, deneysel çalışma sonuçlarına ile yaklaşık \%3,02 hata oranı yaklaşılan optimum hücre sayısı $1,542 \times 10^{6}$ olarak bulunmuş ve optimum olarak kabul edilmiştir. Bu işlemin basamakları ve elde edilen değerler Şekil 3 ile verilmiştir.

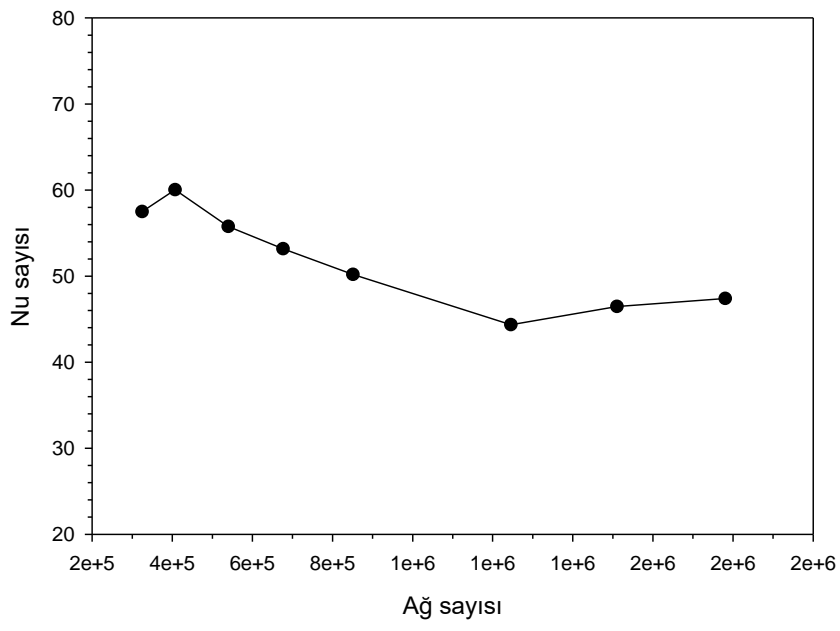

Şekil 3. A $\breve{g}$ sayısı optimizasyonu 


\section{BULGULAR ve TARTIȘMA}

İkili jet sistemi kullanılarak sıcak plakanın hava ile soğutulması durumunun akış karakteristikleri ve hidrolik performansı incelenmiştir. Farklı plaka yüzeylerinde akışın performansının değişimini analiz etmek için düz, yamuk, zigzag ve dikdörtgen kesitte dört farklı plaka yüzeyinin çarpan jetler ile soğutulması işlemi gerçekleştirilmiştir. Türbülanslı akış koşullarında gerçekleştirilen HAD analizleri sonucunda her bir akış koşulunun ortalama ve yerel Nusselt sayıları hesaplanarak grafiksel olarak dağılımları gösterilmiştir. Reynolds sayısının 17000 - 25000 arasında 1000 artış kullanılarak çözümler gerçekleştirilmiştir. Sayısal analiz sonuçları deneysel sonuçlarla karşılaştırılmış ve yaklaşık \%3,1 hata oranıyla deneysel sonuçlara yaklaşılmıştır. Bu değer hesaplamaların sonuçlarının kabul edilebilir olduğunun göstergesidir.

Farklı yüzey biçimleri için Re sayısına göre ortalama $\mathrm{Nu}$ sayısının değişimi Şekil 4'te verilmiştir. Grafikten görüldüğü üzere, Re sayısının artması ile Nu sayısı da belirli bir trend ile artmaktadır. Bütün yüzey şekillerinde görülen bu artış, hava hızının artmasıyla taşınım 1sı transferinin artmasının bir sonucu olarak ortaya çıkmaktadır. Sıcak plakanın şeklinin de Nu sayısı üzerinde önemli bir etkiye sahip olduğu açıkça görülmektedir ki bu da yüzey alanı büyüklüğünün değişimi ile 1sı transferi arsındaki ilişkinin sonucudur. Isı transferi yüzey alanının artması ile yüzeyden gerçekleşen taşınım ısı transferi artmaktadır. Elde edile sonuçlara göre, dikdörtgen biçimli yüzeye sahip sıcak plakanın havanın her hız değerinde en yüksek $\mathrm{Nu}$ sayısına sahip olduğu belirlenmiştir. En yükssek $\mathrm{Nu}$ sayısı dikdörtgen biçimli yüzeyde, $\mathrm{Re}=25000$ değeri için elde edilmiş olup, aynı şartlardaki düz plakanın değerinden yaklaşık $\% 29,2$ daha yüksek olduğu belirlenmiştir.

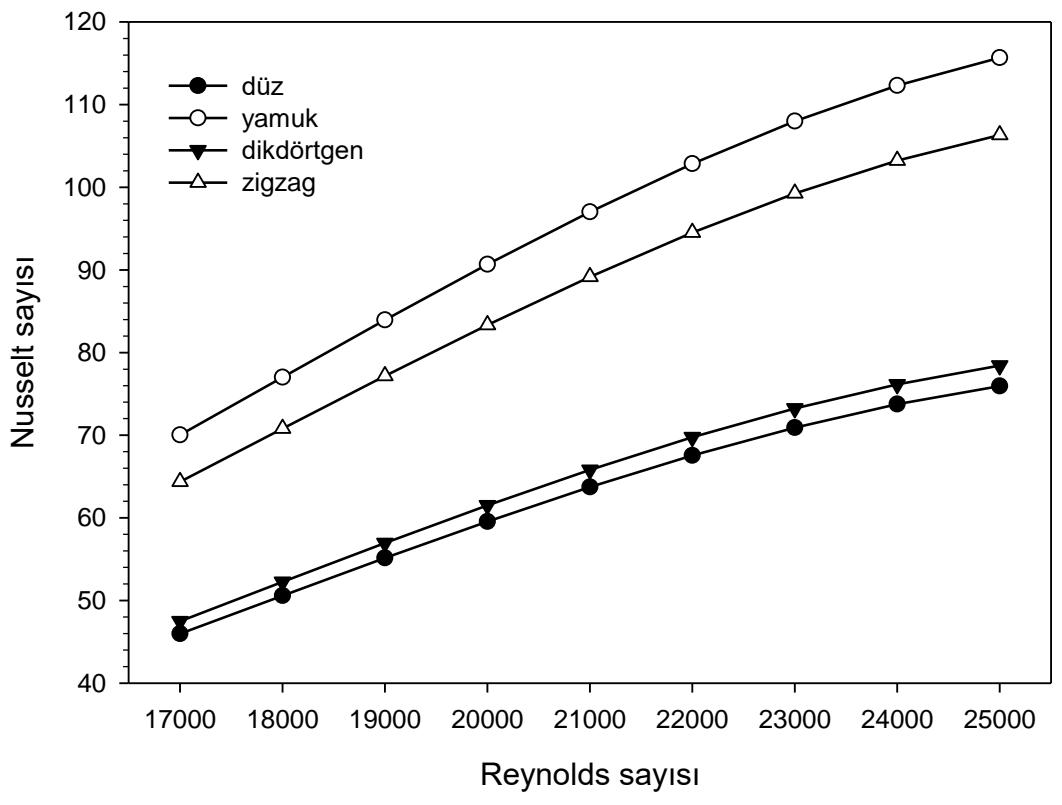

Şekil 4. Hedef yüzey şeklinin ortalama Nu sayısına etkisi

Şekil 5'te farklı yüzey şekilleri için yerel Nu sayısının değişimi verilmiştir. Re sayısının 17000, 21000 ve 25000 değerleri için verilen yerel $\mathrm{Nu}$ sayılarının dağılımı her bir yüzey şekli için benzer eğilim göstermektedir. İkili jet sisteminin orta noktasından çıkış kısımlarına doğru akış bölgesi x-y düzleminde on parçaya bölünmüş ve her bir kısım için yerel Nu sayısı hesaplanmıştır. Grafikte görüldüğüü üzere, iki jet nozulun ortasındaki değer, jetin plakaya çarptığı bölgedeki değerden daha düşüktür. En yüksek yerel Nu sayısı, geometriden de anlaşılacağ üzere havanın, hedef yüzeye ilk çarptığı bölgede elde edilmiştir ki bu da literatür sonuçları ile uyum içerisindedir [15], [16], [20]. İlk çarpma bölgesinde 1sı transferinin yüksek olması sonucunda bu sonuca ulaşılmıştır. 


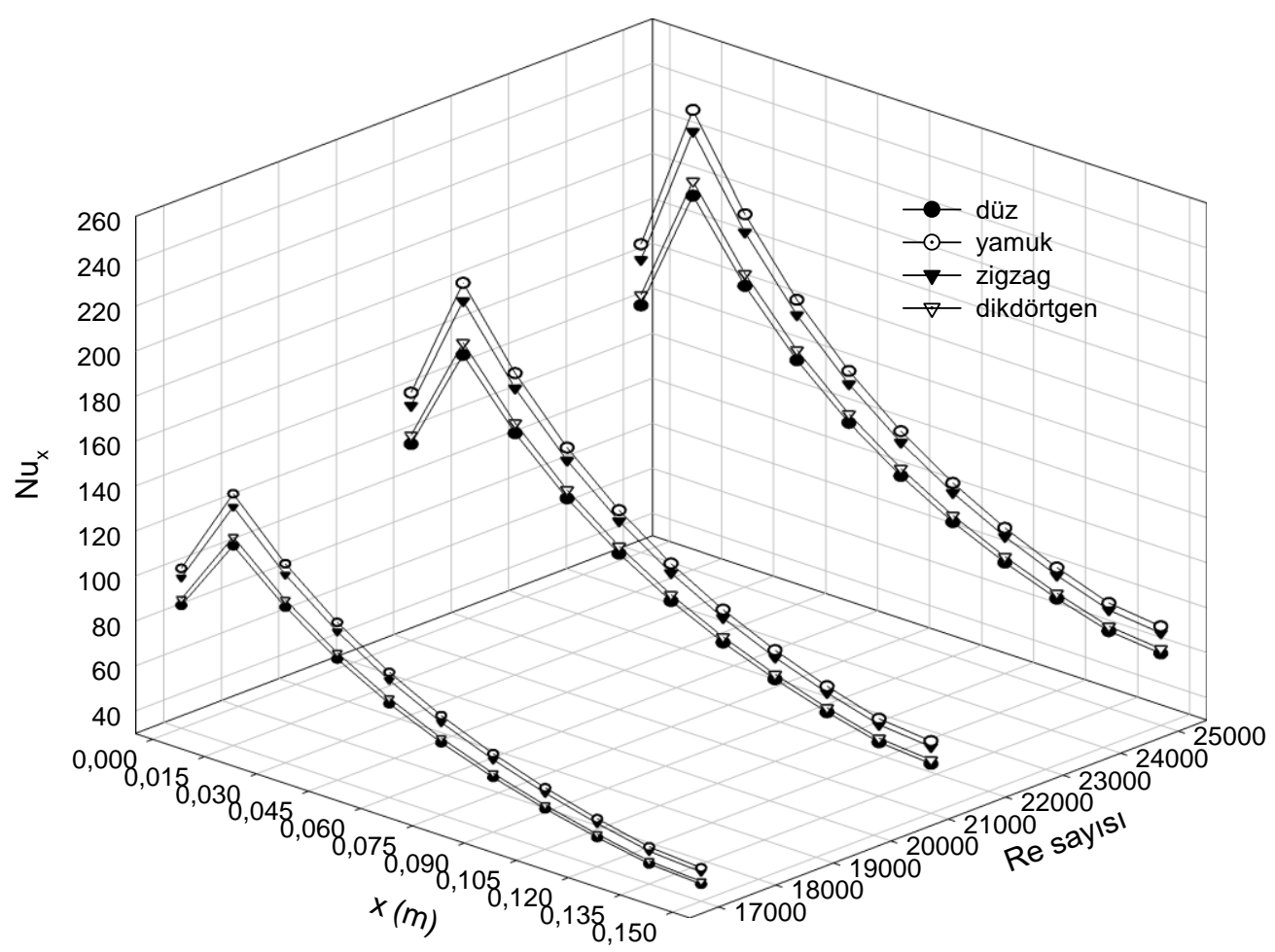

Şekil 5. Yerel Nu sayısının farklı biçimli hedef yüzeyler için Re sayısına göre dă̆llımı

Isı transferini artırmak için yapılan uygulamalar sonucunda hidrodinamik analiz yapılması, sistemin genel performansı hakkında yorum yapabilmek ve yapılan performans artışının basıncı ve pompalama gücünü nasıl etkilediğini tespit etmek açısından önemlidir. Bu yüzden, bu çalışmada akışkan jetlerinin çarptığı hedef yüzeyin farklı şekiller için 1sı transferi analizi yapıldıktan sonra pompalama gücü ve $\mathrm{Nu}_{\text {ort }} / \mathrm{PG}$ oran1 yani 1sıl performans - hidrodinamik performans analizi yapılmıştır. Şekil 6'te farklı yüzey şekline sahip çarpma yüzeyi için gerekli pompalama gücünün Re sayısına göre değişimi verilmiştir. En yüksek pompalama gücü gereken çarpan jet akışı, dikdörtgen kesitli hedef yüzeyde gerçekleşmiştir. Bu durumun en önemli sebebi ise sıcak olan hedef akış yüzey alanının artması ile daha fazla sürtünme kuvvetinin ortaya çıkmasıdır.

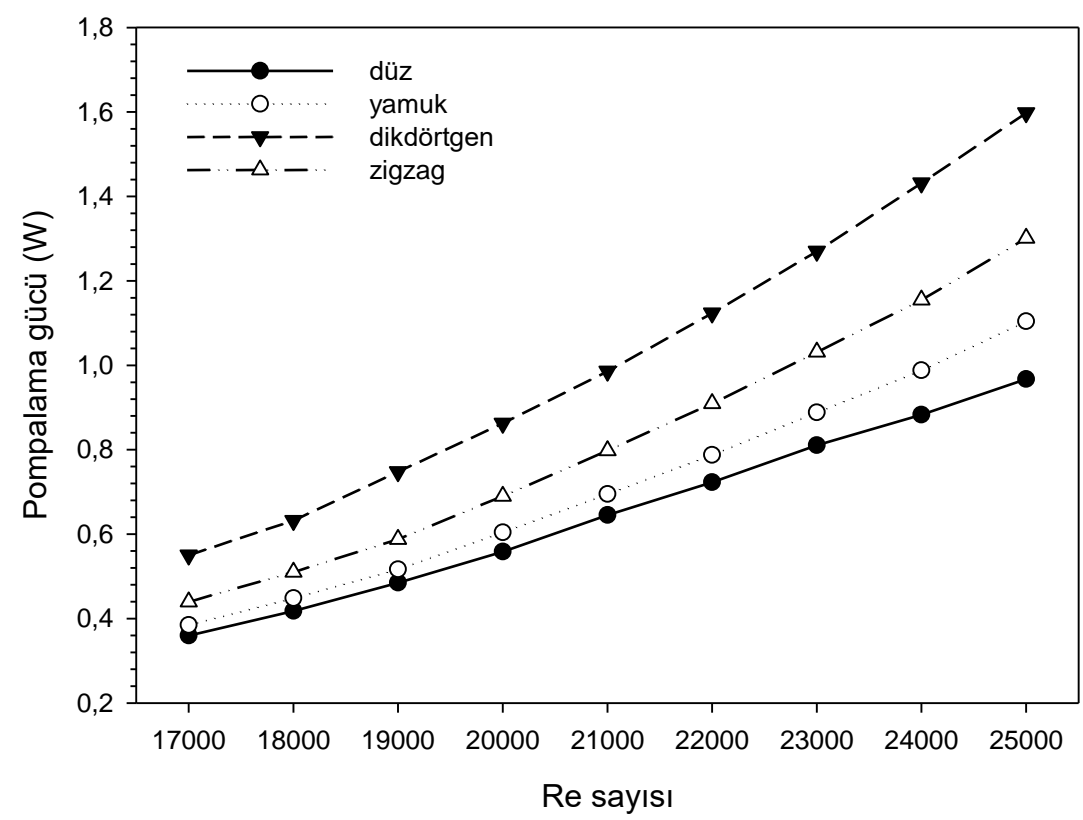

Şekil 6. Yüzey şeklinin pompalama gücüne etkisi 
$\mathrm{Nu}_{\text {ort }} / \mathrm{PG}$ oranının Re sayısı ile değişiminin farklı yüzey geometrisine göre dağılımı Şekil 7'da gösterilmiştir [14]. Re sayısının artmasıyla $\mathrm{Nu}_{\text {ort }} / \mathrm{PG}$ oranının azaldığı açıkça görülmektedir ki bu durum Re sayısının artmasıyla artan $\mathrm{Nu}_{\text {ort }}$ sayısının artma oranının pompalama gücü artışından daha düşük kaldığının göstergesidir. En yüksek $\mathrm{Nu}_{\text {ort }} / \mathrm{PG}$ oranı $\mathrm{Re}=17000$ de yamuk kesitli yüzey için elde edilirken dikdörtgen kesitli hedef yüzeyde bu oran en düşük olarak ortaya çıkmıştır. $147,53 \mathrm{~W}^{-1}$ ile en yüksek $\mathrm{Nu}_{\text {ort }} / \mathrm{PG}$ oranı yamuk kesit için elde edilirken aynı şartlarda dikdörtgen kesitli hedef yüzeyin yaklaşık 1,75 katıdır. Genel anlamda, 1sı transferi açısından bakıldığında akışkan hızı arttığında taşınım ile 1Sı transferi artmaktadır fakat $\mathrm{Nu}_{\text {ort }} / \mathrm{PG}$ oran termo-hidrolik performansın bir göstergesi olduğundan hız arttıkça toplam performansın düştüğü söylenebilir.

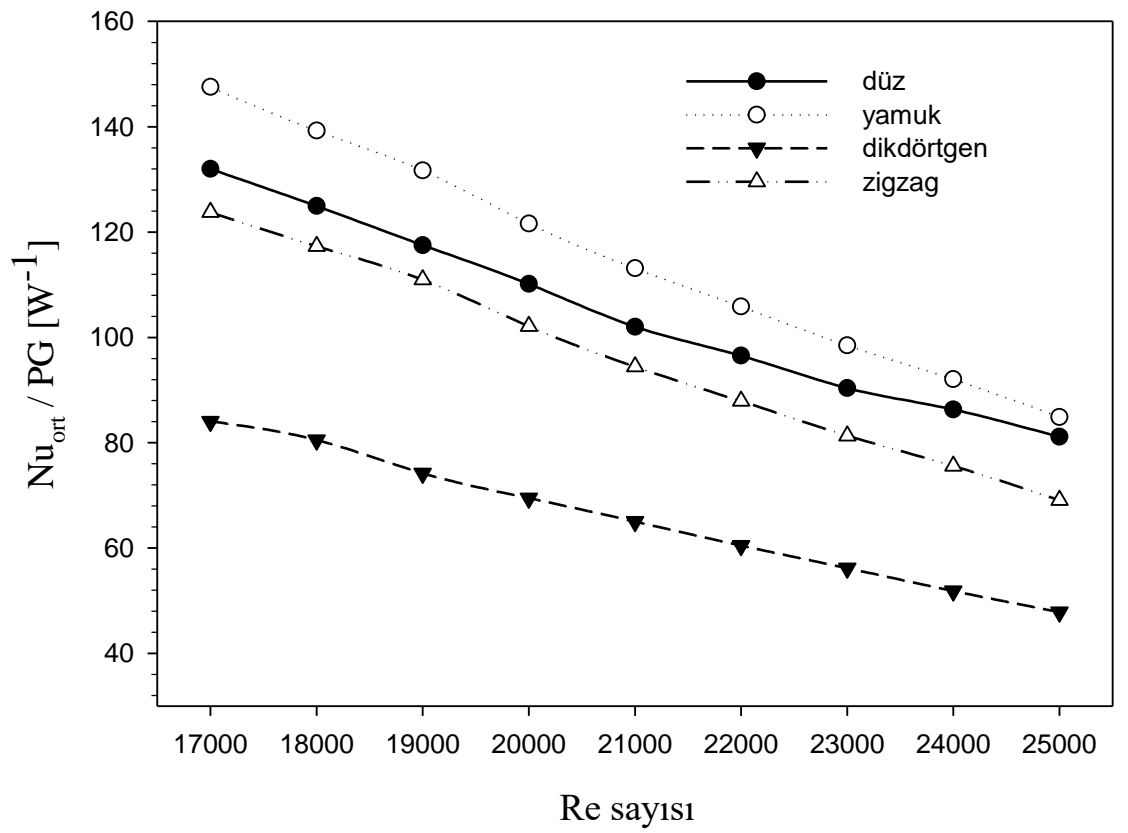

Şekil 7. Nu $u_{\text {orı }} /$ PG oranının farklı yüzey şekilleri için dă̆ıllımı

Şekil 8'de $\operatorname{Re}=25000$ için farklı şekilli çarpma yüzeyleri için elde edilen sıcaklık dağılımları gösterilmiştir. Geriye kalan üç eşit hacimde de aynı dağılım olduğundan, ikili jet sisteminin simetri düzleminden bölünerek 1/4'lük kısmının dağılımları verilmiştir. Her bir kesit için hidrodinamik sınır tabakanın en küçük seviyeden başlayıp kanal boyunca genişlediği görülmektedir. Jet nozulları boyunca sıcaklık değişmediğinden dolayı nozulların bir kısmı şekillerde gösterilmiştir.

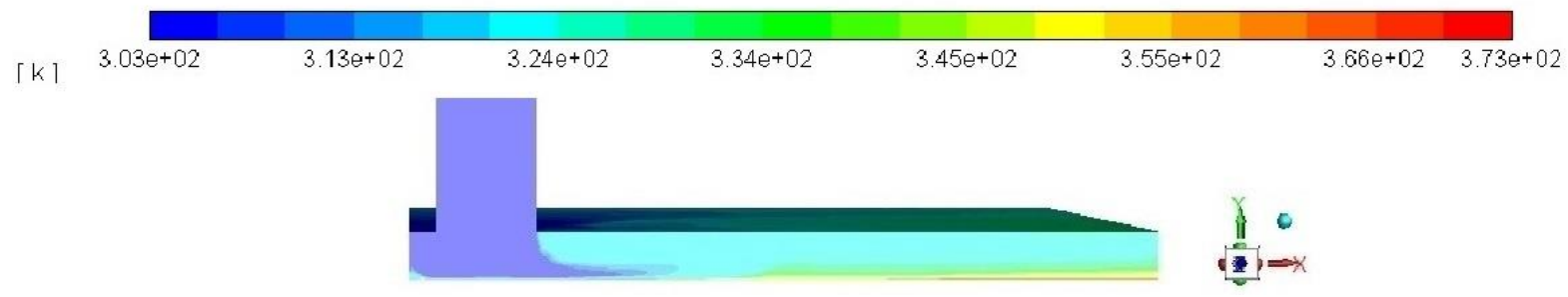

(a)

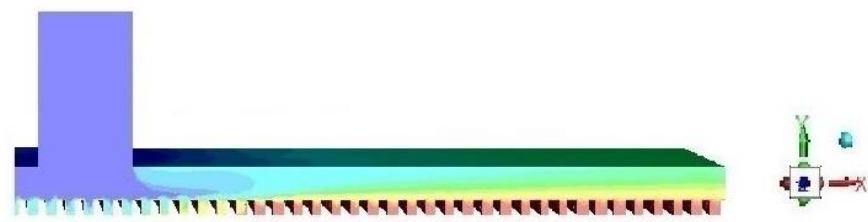

(b) 


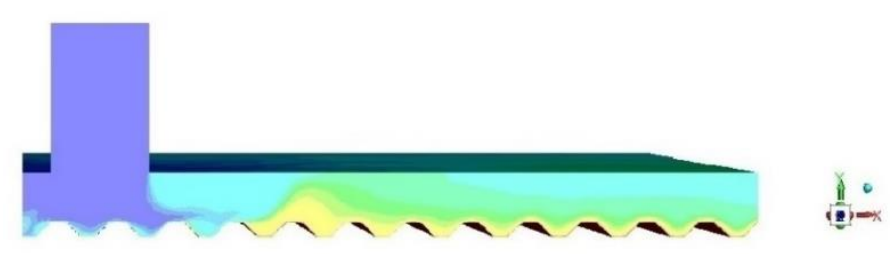

(c)

Şekil 8. Re=25000 için farklı yüzeylerdeki sıcaklık dağllımları (a) düz, (b) dikdörtgen, (c) yamuk

Şekil 9'da zigzag çarpma yüzeyi için Re sayısının 17000, 21000 ve 25000 değerlerindeki sıcaklık dağılımları gösterilmiştir. Akışkan hızı arttıkça hidrodinamik tabaka kalınlığı da küçülmektedir. Bütün yüzeyler için aynı şekilde elde edilmiştir. Ayrıca, şekillerde görüldüğü üzere, termal sınır tabakası kalınlığı duvar jet bölgesinde daha incedir ve kanal uzunluğu boyunca gelişmektedir. Reynolds sayısının artmasıyla sıcaklığın en yüksek olduğu bölge, duvar jet bölgesinden kanal çıkışına doğru hareket etmektedir.

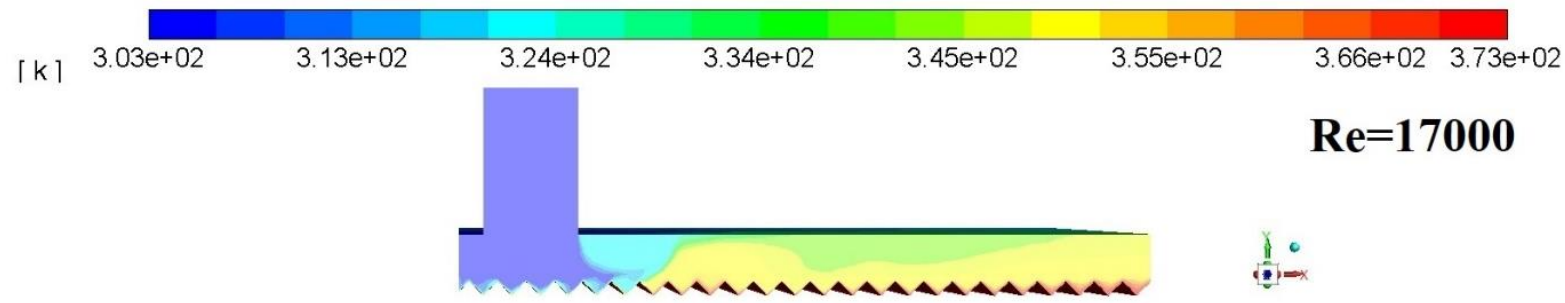

(a)

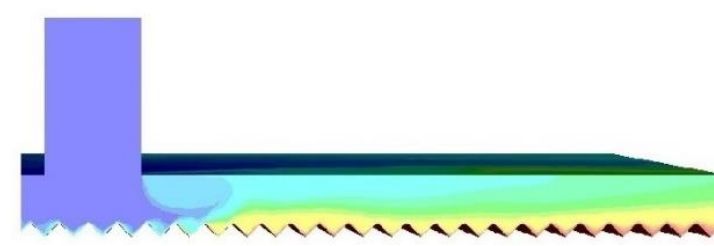

(b)

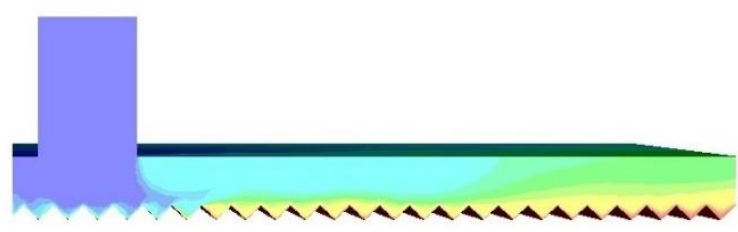

(c)

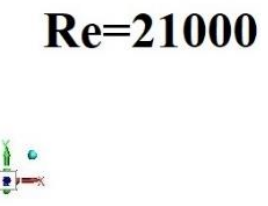

$\mathbf{R e}=\mathbf{2 5 0 0 0}$

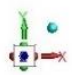

Şekil 9. Zigzag kesitli yüzeydeki sıcaklık dağllımları (a) Re=17000, (b) $R e=21000$, (c) $R e=25000$

\section{IV.SONUCLAR}

Çarpan jet akışı için türbülanslı akış koşullarında farklı kesit şekillerine sahip (düz, yamuk, zigzag ve dikdörtgen) sıcak yüzeylerin 1sı transferi performansı sayısal olarak incelenmiştir. Farklı şekilli yüzeylerin ortalama $\mathrm{Nu}$ sayısında, düz yüzeye göre yaklaşı \%50'nin üzerinde artış olduğu tespit edilmiştir. Yerel Nu sayısı en yüksek olarak, Re $=25000$ değeri için yamuk kesitli hedef yüzey için nozul çarpma bölgesinde elde edilmiştir. Aynı şekilde, hidrodinamik performans ölçütü olan Nu/PG oranı da yamuk kesitli yüzey için elde edilmiştir ve en düşük değer dikdörtgen kesitli yüzey için ortaya çıkmıştır. Bunun nedeni basınç değişiminin oldukça yüksek olmasıdır. Yamuk kesit için bu oran $R e=17000$ için en yüksek olup aynı şartlardaki dikdörtgen kesit değerinden yaklaşı \%75 yüksektir. 


\section{KAYNAKLAR}

[1] M. J. S. De Lemos and C. Fischer, "Thermal analysis of an impinging jet on a plate with and without a porous layer," Numer. Heat Transf. Part A Appl., vol. 54, no. 11, pp. 1022-1041, 2008.

[2] M. Kılıç and H. M. Ali, "Numerical investigation of combined effect of nanofluids and multiple impinging jets on heat transfer," Therm. Sci., vol. 2018, no. 5, pp. 3165-3173, 2018.

[3] İ. Dağtekin and H. F. Öztop, "Heat transfer due to double laminar slot jets impingement onto an isothermal wall within one side closed long duct," Int. Commun. Heat Mass Transf., vol. 35, no. 1, pp. 65-75, 2008.

[4] V. Katti and S. V. Prabhu, "Heat transfer enhancement on a flat surface with axisymmetric detached ribs by normal impingement of circular air jet," Int. J. Heat Fluid Flow, vol. 29, no. 5, pp. 1279-1294, 2008.

[5] S. A. Nada, "Slot/slots air jet impinging cooling of a cylinder for different jets-cylinder configurations," Heat Mass Transf. und Stoffuebertragung, vol. 43, no. 2, pp. 135-148, 2006.

[6] N. Singh, R. Sivan, M. Sotoa, M. Faizal, and M. R. Ahmed, "Experimental studies on parallel wavy channel heat exchangers with varying channel inclination angles," Exp. Therm. Fluid Sci., vol. 75, pp. 173-182, 2016.

[7] H. G. Lee, H. S. Yoon, and M. Y. Ha, "A numerical investigation on the fluid flow and heat transfer in the confined impinging slot jet in the low Reynolds number region for different channel heights," Int. J. Heat Mass Transf., vol. 51, no. 15-16, pp. 4055-4068, 2008.

[8] B. K. Rim, N. M. Saïd, H. Bournot, and G. Le Palec, "Effect of nozzle-to-plate spacing on the development of a plane jet impinging on a heated plate," Heat Mass Transf. und Stoffuebertragung, vol. 53, no. 4, pp. 1305-1314, 2017.

[9] M. Attalla and M. Salem, "Experimental investigation of heat transfer for a jet impinging obliquely on a flat surface," Exp. Heat Transf., vol. 28, no. 4, pp. 378-391, 2015.

[10] A. M. Achari and M. K. Das, "Conjugate heat transfer study of a turbulent slot jet impinging on a moving plate," Heat Mass Transf. und Stoffuebertragung, vol. 53, no. 3, pp. 1017-1035, 2017.

[11] Y. H. Kim, D. H. Lee, and S. H. Han, "Investigation of impingement surface geometry effects on heat transfer in a laminar confined impinging slot jet," Int. J. Heat Mass Transf., vol. 115, pp. 347$353,2017$.

[12] M. Rajabi Zargarabadi, E. Rezaei, and B. Yousefi-Lafouraki, "Numerical analysis of turbulent flow and heat transfer of sinusoidal pulsed jet impinging on an asymmetrical concave surface," Appl. Therm. Eng., vol. 128, pp. 578-585, 2018.

[13] T. Park, K. Kara, and D. Kim, "Flow structure and heat transfer of a sweeping jet impinging on a flat wall," Int. J. Heat Mass Transf., vol. 124, pp. 920-928, 2018.

[14] A. Ü. Tepe, K. Arslan, Y. Yetişken, and Ü. Uysal, "Effects of extended jet holes to heat transfer and flow characteristics of the jet impingement cooling," J. Heat Transfer, vol. 141, no. 8, pp. 1-14, 2019.

[15] R. Ekiciler, M. S. A. Çetinkaya, and K. Arslan, "Convective heat transfer investigation of a confined air slot-jet impingement cooling on corrugated surfaces with different wave shapes," J. Heat 
Transfer, vol. 141, no. 2, pp. 1-7, 2019.

[16] M. Kılıç and Ş. Başkaya, "Farklı geometride akış yönlendiriciler ve çarpan jet kullanarak yüksek 1S1 ak1lı bir yüzeyden olan 1S1 transferi iyileştirilmesi," Gazi Üniversitesi Mühendislik-Mimarlık Fakültesi Derg., vol. 32, no. 3, pp. 693-707, 2017.

[17] T. Çalışır, S. Çalışkan, M. Kılıç, and Ş. Başkaya, "Çarpan akışkan jetleri kullanarak kanatçıklı yüzeyler üzerindeki akış alanının sayısal olarak incelenmesi," J. Fac. Eng. Archit. Gazi Univ., vol. 32, no. 1, pp. 127-138, 2017.

[18] A. Javadi, "Numerical study of an impinging jet in cross-flow within and without influence of vortex generator structures on heat transfer," Heat Mass Transf. und Stoffuebertragung, vol. 56, no. 3, pp. 797-810, 2020.

[19] M. A. R. Sharif and K. K. Mothe, "Evaluation of turbulence models in the prediction of heat transfer due to slot jet impingement on plane and concave surfaces," Numer. Heat Transf. Part B Fundam., vol. 55, no. 4, pp. 273-294, 2009.

[20] M. Faris, H. Kareem, R. Zulkifli, and Z. Harun, "Heat transfer and flow structure of multiple jet impingement mechanisms on a flat plate for turbulent flow," Int. J. Mech. Mechatronics Eng., vol. 19, no. 3, pp. 141-160, 2019. 